\title{
TISSUE TRANSGLUTAMINASE AUTOANTIBODY DETECTION IN HUMAN SALIVA: A POWERFUL METHOD FOR CELIAC DISEASE SCREENING
}

\author{
Margherita bonamico, mD, Mirella Ferri, mD, Raffaella Nenna, mD, Antonella Verrienti, BSc, \\ UMberto DI Mario, MD, PhD, AND ClaUdio TiBerti, BSCS
}

Objective To test the possibility of detecting tissue transglutaminase autoantibodies (tTG-Abs) in saliva with a novel sensitive fluid-phase radioimmunoassay (RIA).

Study design Paired saliva and serum samples from 39 patients with celiac disease (CD), at the first biopsy (Group 1: 28 females, mean age $11.5 \pm 11.1$ years); 32 controls with a normal duodenal mucosa (Group 2: 18 females, mean age $8.1 \pm 3.6$ years); and 32 healthy volunteers (Group 3: 21 females, mean age 31.7 \pm 9.8 years) were studied for tTG-Ab presence. Limit of positivity for salivary assay was calculated according to the 99th percentiles of Group 2 control children and was expressed as an autoantibody (Ab) index.

Results Salivary tTG-Abs were found in $\mathbf{9 7 . 4 \%}$ of the patients with CD and in $100 \%$ of the corresponding serum samples. All Group 3 subjects were negative with both saliva and serum assays. A correlation between saliva and serum tTG-Ab titers was found $(\mathrm{r}=0.826, P=.0014)$.

Conclusions This study demonstrates that it is possible to detect salivary tTG-Abs in CD with a non-invasive, simple to perform, reproducible and sensitive method. (J Pediatr 2004;144:632-6)

eliac disease (CD) may appear in a classic presentation, with gastrointestinal complaints and growth failure or with extraintestinal manifestations and "atypical forms"1 characterized by anemia and short stature, ${ }^{2,3}$ or with a silent form, more frequent in first-degree relatives of patients with CD. ${ }^{4}$ The prevalence of CD is increased in subjects with elevated aminotransferase levels, ${ }^{5,6}$ autoimmune diseases, ${ }^{7,8}$ and chromosomal aberrations. ${ }^{9,10}$ Complications of long-standing CD may include osteopathy, ${ }^{11}$ endocrinopathy, ${ }^{12}$ infertility, low birth weight infants, ${ }^{13,14}$ cancer, ${ }^{15}$ and dilated cardiomyopathy and other forms of heart failure. ${ }^{16} \mathrm{CD}$ has a high prevalence in the general population $(0.55 \%$ in Italy), often in an asymptomatic form. ${ }^{17}$ To reduce the risks associated with prolonged gluten exposure, $\mathrm{CD}$ should be diagnosed early, on the basis of the result of one or more intestinal biopsies. ${ }^{18}$ Patients with $\mathrm{CD}$ receiving a gluten-containing diet have increased levels of anti-gliadin (AGA), anti-endomysium (EMA), ${ }^{19}$ and anti-tissue transglutaminase autoantibodies (anti-tTG-Ab). ${ }^{20}$ Serum AGA have proved to be effective in the identification of children at risk for $\mathrm{CD}$, but less so in adult screening. ${ }^{21} \mathrm{EMA}$ are more specific than AGA but are observer-dependent, and sometimes they are not found in children with CD younger than aged 2 years. ${ }^{19}$ The recent identification of tTG as the main autoantigen recognized by $\mathrm{EMA}^{22}$ has lead to the development of various studies that suggest an important role for this enzyme in the etiopathogenesis of CD. ${ }^{23,24}$ Several methods have been proposed for the detection of humoral anti-tTG immunoreactivity in CD. ${ }^{20,25-27}$ The most sensitive assays to detect tTG-Abs were those using human recombinant $\mathrm{tTG}$ in a fluid-phase radioimmunoassay (RIA) format. ${ }^{26,27}$ Attempts have been made in assaying $\mathrm{CD}$-related $\mathrm{Ab}$ in saliva, ${ }^{28-35}$ which are easily obtained by noninvasive techniques, bypassing blood sample collection. However, the proposed salivary assays were not accurate enough, suggesting that saliva is not suitable for CD screening

\begin{tabular}{llll}
\hline $\mathrm{Ab}$ & Autoantibody & $\lg \mathrm{A}$ & Immunoglobulin A \\
$\mathrm{AGA}$ & Anti-gliadin & RIA & Radioimmunoassay \\
$\mathrm{CD}$ & Celiac disease & ROC & Receiver operator characteristic \\
EMA & Anti-endomysium & tTG-Abs & Tissue transglutaminase autoantibodies \\
\hline
\end{tabular}

From Institute of Paediatrics and Department of Clinical Science, University of Rome "La Sapienza," Italy. Supported in part by a grant from the Ministero dell'Università, dell'Istruzione e della Ricerca (MUIR) and by a grant from the Ministero della Sanità. Submitted for publication Apr 29, 2003; last revision received Dec 3, 2003; accepted Jan 12, 2004.

Reprint requests: Prof. Margherita Bonamico, Istituto di Clinica Pediatrica, Policlinico "Umberto I," Viale Regina Elena 324, 0016I Rome, Italy. E-mail: margherita.bonamico@ uniromal.it.

0022-3476/\$ - see front matter

Copyright (c) 2004 Elsevier Inc. All rights reserved.

10.1016/j.jpeds.2004.01.035 
purposes. The aim of this study was to detect tTG-Abs in human saliva using a new fluid-phase RIA, the results of which were compared with those obtained in serum with a highly sensitive RIA and with an indirect immunofluorescence EMA assay.

\section{MATERIAL AND METHODS}

\section{Subjects}

Patients with $\mathrm{CD}$ and control subjects were enrolled sequentially from November 2001 to November 2002 from the Pediatric Clinic referral center of the University of Rome "La Sapienza." Paired saliva and serum samples were collected from a total of 103 (not immunoglobulin A [IgA] deficient) subjects subdivided in three groups: (1) Group 1: $39 \mathrm{symp}-$ tomatic subjects with $\mathrm{CD}$ (with typical or atypical symptoms, 28 females, mean age $11.5 \pm 11.1$ years) with endoscopic diagnosis of the disease, all receiving a gluten-containing diet; (2) Group 2: 32 control subjects (18 females, mean age $8.1 \pm 3.6$ years) who underwent upper endoscopy for gastroesophageal reflux disease or chronic abdominal pain; and (3) Group 3: 32 healthy volunteers (21 females, mean age $31.7 \pm 9.8$ years). No family members were present in the three groups investigated.

Group 1 and Group 2 subjects underwent routine endoscopy and biopsy. For biopsy histological examination, one specimen was taken from the duodenal bulb and four specimens were taken from the second and third duodenal portion. All these samples were evaluated subsequently by a single pathologist experienced in CD scoring. Group 1 patients, all symptomatic, showed total/subtotal villous atrophy of the duodenal mucosa, whereas Group 2 subjects showed a normal duodenal mucosa. All parents/guardians gave informed consent for the participation of the children in the study as did all adult subjects. The study was approved by the Ethics Committee at the Pediatric Clinic, University of Rome "La Sapienza.”

\section{Collection and Treatment of Serum and Saliva Samples}

The subjects investigated were not allowed to eat or smoke during the morning of serum and saliva collection between $8 \mathrm{AM}$ and $11 \mathrm{AM}$. Serum samples were aliquoted and were stored at $-20^{\circ} \mathrm{C}$ until analysis. Unstimulated whole saliva samples of 94/103 subjects participating in the study were obtained by direct spitting into a sterile plastic tube in a period of time not exceeding 10 minutes, were collected in ice, and subsequently were spinned within 2 hours at 10000 rpm for 10 minutes at $4^{\circ} \mathrm{C}$. After supernatant collection, these samples were aliquoted and stored at $-80^{\circ} \mathrm{C}$ until analysis. Unstimulated whole saliva samples of $9 / 103$ subjects who were too young to spit into a tube (5 Group 1 and 4 Group 2 subjects, age range 1.1-4.0 years), were collected close to parotid's duct orifice by gentle aspiration with a needle-free syringe. These saliva samples subsequently were treated as the other 94 saliva samples.

\section{EMA Method}

EMA IgA were tested in sera diluted 1:5 by an indirect immunofluorescence method using as a substrate sections from the distal portion of monkey esophagus (Eurospital, Trieste, Italy). ${ }^{19}$

\section{Serum tTG-Ab RIA}

The full-length human tTG cDNA (kindly provided by Prof. George Eisenbarth, Barbara Davis Center for Childhood Diabetes, University of Colorado Health Science Center, Denver, Colo) was transcribed and translated in vitro in the presence of ${ }^{35} \mathrm{~S}$-methionine (NEN, Life Science Products Inc) using the TNT-coupled transcription-translation system (Promega, Madison, Wis). tTG-Ab presence was detected by a previously published RIA method, where a receiver operator characteristic (ROC) analysis was used to identify the optimal threshold value for sensitivity and specificity. ${ }^{27} \mathrm{Ab}$ levels were expressed as an $\mathrm{Ab}$ index calculated as follows: (sample counts per minute [cpm] negative standard sample cpm)/(positive standard control cpm - negative standard control cpm). Serum samples were considered $\mathrm{tTG}-\mathrm{Ab}$-positive if the $\mathrm{Ab}$ index was above 0.050. Serum samples with a tTG-Ab-positive index $\geq 0.300$ were considered highly positive.

\section{Saliva tTG-Ab RIA}

The principle of the method used to detect $\mathrm{tTG}-\mathrm{Abs}$ in saliva is similar to the one utilized for serum samples. ${ }^{27}$ Briefly, $\left[{ }^{35} \mathrm{~S}\right]$-methionine tTG was incubated at $4{ }^{\circ} \mathrm{C}$ with $30 \mu \mathrm{L}$ of saliva sample diluted in buffer solution. Twenty-five microliters of goat anti-human IgA-Agarose (Sigma, St. Louis, Mo) were added subsequently to separate free from $\mathrm{Ab}$-bound labeled products. After overnight rotation, repeated washings, spinning at $1.000 \mathrm{rpm}$, and aspiration of the supernatant, a SDS was added to each tube to resuspend the pellet that was then transferred into a scintillation vial. This last step was repeated another time. Each vial was then counted in a $\beta$ counter after the addition of scintillation liquid solution (Pakard, Meriden, Conn). tTG-Ab saliva levels were calculated and expressed as in the serum RIA. To detect the optimal saliva volume to be used in our assay we studied, in various experiments, the anti-tTG immunoreactivity of a total of 12 saliva samples originating from $6 \mathrm{tTG}-\mathrm{Ab}$-positive patients with $\mathrm{CD}$ and 6 tTG-Ab-negative healthy control subjects. We tested different saliva concentrations of each sample (range $2-150 \mu \mathrm{L}$ ) and found that $30 \mu \mathrm{L}$ was the saliva volume that was best able to discriminate between tTG-Abpositive and tTG-Ab-negative subjects. Figure 1 depicts the optimal saliva volume to be used in the assay and represents data from 5 subjects (3 patients with $\mathrm{CD}$ and 2 healthy subjects) studied in a similar experiment.

\section{Statistical Analysis}

The Mann-Whitney nonparametric $U$ test was used to determine differences between groups. A two-tailed $P<.05$ 


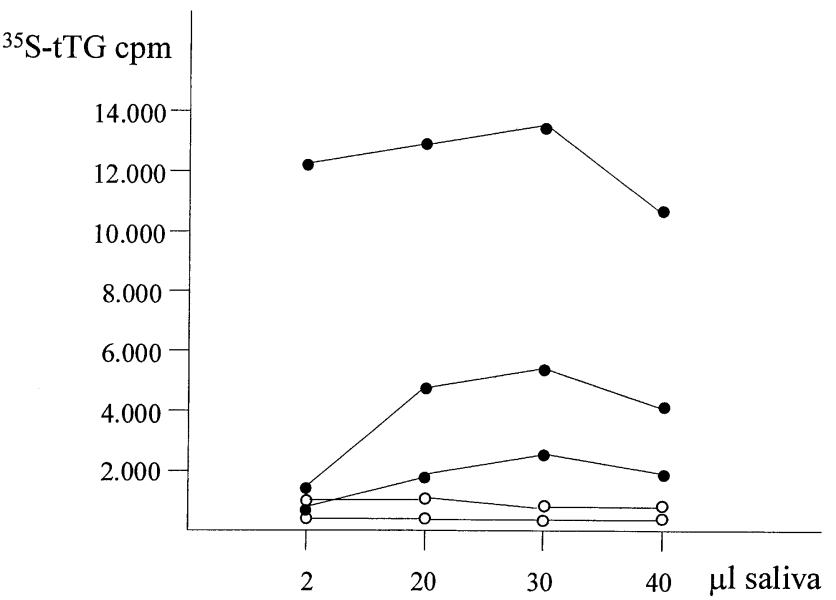

Fig I. Detection of the optimal saliva volume to be used in the salivary RIA method. The $\mathrm{x}$-axis represents the different saliva amounts (in $\mu \mathrm{L}$ ) tested with the fluid-phase RIA method. Filled circles represent $\mathrm{CD}$ tTGAb-positive patients; empty circles represent $\mathrm{CD}$ tTGAb-negative control subjects.

was considered significant. Correlation between the results obtained with the serum tTG-Ab RIA and the saliva tTG-Ab RIA was examined with linear regression analysis. Saliva tTG$\mathrm{Ab}$ RIA method sensitivity and specificity were analysed as a ROC plot. ${ }^{36}$

\section{RESULTS}

\section{EMA in Serum}

EMA IgA positivity was detected in 37 of 39 (94.9\%) Group 1 patients with CD. No EMA positivity was detected in Group 2 or Group 3 subject sera.

\section{tTGAbs in Serum}

Using previously ROC-plot-established thresholds, corresponding to the 99 th percentile of a control population, ${ }^{27}$ 39 of 39 (100\%) Group 1 patients with CD had serum tTGAbs (Fig 2, left side) with a mean $\mathrm{Ab}$ index of $0.783 \pm 0.356$; 35 of 39 (89.7\%) Group 1 patients with CD had high tTG-Ab titers. tTG-Abs were not detected in Group 2 and Group 3 subject sera. Group I serum tTG-Ab titers were significantly higher than Group 2 (mean $\mathrm{Ab}$ index $0.003 \pm 0.013$, $P<.0001$ ) and Group 3 (mean $\mathrm{Ab}$ index $0.004 \pm 0.011$, $P<.0001)$ control subjects. The diagnostic performance of the serum tTG-Ab RIA test, calculated on the basis of Group 1 and Group 2 subject results, was $100 \%$ in sensitivity and $100 \%$ in specificity.

\section{tTGAbs in Saliva}

Thirty-eight of 39 (97.4\%) Group 1 subjects with CD had tTG-Abs (Fig 2, right side) with a mean $\mathrm{Ab}$ index of $0.373 \pm 0.338$. The optimal cutoff calculated by the ROC plots, corresponding to the 99th percentile of Group 2 subject values, was 0.061 . The intra-assay and inter-assay coefficients of variation of the method were $4.6 \%$ and $15.1 \%$, respectively.

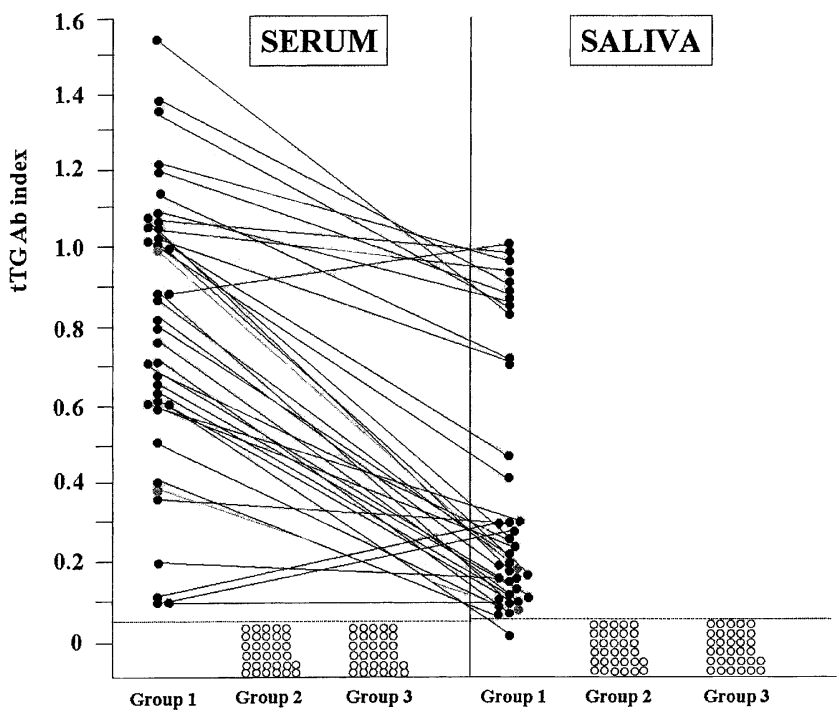

Fig 2. Serum (left side) and salivary (right side) IgA anti-tTGAbs. The $y$-axis represents the tTGAbs titers expressed as an autoantibody index. The $x$-axis represents the three groups of subjects investigated: CD patients at diagnosis (Group 1), CD age-matched gastroenterologic control subjects (Group 2), and healthy volunteers (Group 3). The dotted lines represent the cut-off level of the two methods. Empty grey circles represent Group $1 \mathrm{CD}$ patients found serum- and saliva-tTGAb RIA-positive, but serum-EMA-negative.

The saliva tTG-Ab titers of Group 1 patients with $\mathrm{CD}$ were significantly higher compared with Group 2 (mean $\mathrm{Ab}$ index $-0.004 \pm 0.041, P<.0001$ ) and with Group 3 (mean Ab index $-0.024 \pm 0.049, P<.0001)$ subjects. None of the healthy volunteers (Group 3) was found to be $\mathrm{tTG}-\mathrm{Ab}$ positive. The specificity of the saliva versus serum RIA was $100 \%$, whereas the sensitivity was $97.4 \%$. A significant correlation $(r=0.826$, $P=.0014$ ) between serum and saliva anti-tTG-Ab levels was found. The 2 Group 1 subjects with CD who were EMAnegative were found to be tTG-Ab positive with saliva as well as with serum RIA assays, whereas only 1 Group 1 EMApositive subject with $\mathrm{CD}$ was found to be tTG-Ab-positive with serum but not with the salivary RIA method.

\section{DISCUSSION}

This study demonstrates that, using a fluid-phase RIA on human saliva samples, it is possible to detect $\mathrm{tTG}$-Abs in active CD. The sensitivity and specificity of the method are comparable to those obtained with a highly sensitive serum RIA. The sensitivity is higher than that of the serum EMA method. The limit of positivity of our method, calculated in Group 2 children, is valid, as shown by Group 3 healthy volunteers. There are no technical aspects limiting the applicability of this new method, including the saliva collection and the assay procedure, which employs instruments commonly used in the clinical research laboratory. The idea of developing a fluid-phase RIA to detect salivary anti-tTG human antibodies originated from two considerations. The first was that human saliva is a specimen of potentially great interest for disease screening and monitoring. It can be 
obtained easily and repeatedly by non-invasive techniques, with a limited factor risk in respect to blood-borne infections for healthcare personnel. The second consideration was that among the several immunoassays developed to detect antitTG-Abs in $\mathrm{CD}$, evidence indicated that those working in fluid-phase were the most specific and sensitive. This was probably a result of the presence of conformational domains in the $\mathrm{tTG}$ protein ${ }^{37,38}$ that seem to be better preserved in fluidphase rather than in solid-phase procedures. ${ }^{27}$ Previously, several attempts were made to detect salivary $\mathrm{CD}$-specific antibodies, in particular AGA and EMA. ${ }^{28-34}$ AGA detection had generally low sensitivity, and when used to screen children with $\mathrm{CD}$, also a limited specificity. ${ }^{28-35}$ IgA EMA were evaluated in saliva fluid in two studies performed with indirect immunofluorescence methods. ${ }^{33,34}$ Lätheenoja et $\mathrm{al}^{33}$ failed to detect a salivary EMA immune response in all the subjects with $\mathrm{CD}$ investigated at disease diagnosis; they postulated that salivary IgA EMA are not produced locally. Di Leo et $\mathrm{al}^{34}$ could detect EMA in untreated children with $\mathrm{CD}$ in concentrated saliva samples but only with a low sensitivity. Therefore, the two groups concluded that saliva cannot be considered as a valid screening tool for CD. Salivary IgA, which are the immunoglobulins most represented in normal whole saliva, ${ }^{39}$ are significantly higher in patients with $C D$ with respect to healthy controls, but their concentration is about 10 times lower than in serum. We found that, in order to evaluate $\mathrm{IgA}$ anti-tTG presence, the optimal saliva volume to be used in our assay is 15 times more with respect to the volume used in the serum RIA. It is possible that the previously reported low sensitivity in detection of salivary CD-related antibodies also was the result of, in addition to the use of non-fluid-phase RIA methods, assays performed with inappropriate saliva volumes.

In conclusion, our study demonstrated that it is possible to detect salivary tTG-Abs with high specificity and sensitivity using a simple, reproducible fluid-phase RIA method. The immune changes typical of $\mathrm{CD}$ may be reflected in oral secretions, the mouth being an integrated part of the upper gastrointestinal tract. Saliva, a specimen that can be collected easily by non-invasive procedures, may be a reliable, powerful tool for the screening of CD.

We are grateful to Prof Gerolamo Gemme for the invaluable contribution and to Benedetta Fiore, Maurizio Passariello, Enina Thanasi, Mirka Guido, and Anina Werner for the excellent technical and clinical assistance.

\section{REFERENCES}

1. Branski D, Troncone R. Celiac disease: a reappraisal. J Pediatr 1998; 133:181-7.

2. Bonamico M, Vania A, Monti S, et al. Iron deficiency in children with celiac disease. J Pediatr Gastroenterol Nutr 1987;6:702-6.

3. Bonamico $M$, Scirè $G$, Mariani $P$, et al. Short stature as the primary manifestation of monosymptomatic celiac disease. J Pediatr Gastroenterol Nutr 1992;14:12-6.

4. Auricchio S, Mazzacca G, Tosi R, Visakorpi J, Maki M, Polanco I. Celiac disease as a familiar condition: identification of a symptomatic celiac patients within family group. Gastroenterol Int 1988;1:25-31.
5. Bonamico M, Pitzalis G, Culasso F, et al. Il danno epatico nella malattia celiaca del bambino. Minerva Pediatr 1986;38:959-62.

6. Volta U, De Franceschi L, Lari F, Molinaro N, Zoli M, Bianchi FB. Coeliac disease hidden by cryptogenic hypertransaminasaemia. Lancet 1998;352:26-9.

7. Collin P, Salmi J, Hallstrom O, Reunala T, Pasternack A. Autoimmune thyroid disorders and coeliac disease. Eur J Endocrinol 1994;130:137-40.

8. Holmes GK. Screening for coeliac disease in type 1 diabetes. Arch Dis Child 2002;87:495-8.

9. Bonamico M, Mariani P, Danesi HM, et al. Prevalence and clinical picture of celiac disease in Italian Down syndrome patients: a multicenter study. SIGEP and Medical Genetic Group. J Pediatr Gastroenterol Nutr 2001;33:139-43.

10. Bonamico M, Pasquino AM, Mariani $P$, et al. Prevalence and clinical picture of celiac disease in Turner syndrome. J Clin Endocrinol Metab 2002;87:5495-8.

11. Gonzalez D, Mazure R, Mautalen C, Vazquez H, Bai J. Body composition and bone mineral density in untreated and treated patients with celiac disease. Bone 1995;16:231-4.

12. Kumar V, Rajdhyaksha M, Worsman J. Celiac disease associated autoimmune endocrinopathies. Clin Diagn Lab Immunol 2001;8:678-85.

13. Ferguson R, Holmes GK, Cooke WT. Coeliac disease, fertility, and pregnancy. Scand J Gastroenterol 1982;17:65-8.

14. Ciacci C, Cirillo M, Auriemma G, Di Dato G, Sabbatini F, Mazzacca G. Coeliac disease and pregnancy outcome. Am J Gastroenterol 1996;91: 718-22.

15. Loftus CG, Loftus EV. Cancer risk in celiac disease. Gastroenterology 2002;123:1726-69.

16. Prati D, Bardella MT, Peracchi M, et al. High frequency of antiendomysial reactivity in candidates to heart transplant. Dig Liver Dis 2002; 34:39-43.

17. Catassi C, Fabiani E, Ratsch IM, et al. The coeliac iceberg in Italy. A multicentre antigliadin antibodies screening for coeliac disease in schoolage subjects. Acta Paediatr Suppl 1996;412:29-35.

18. Walker-Smith JA, Guandalini S, Schmitz J, Shmerling DH, Visakorpi JK. Revised criteria for diagnosis of coeliac disease. Arch Dis Child 1990;65:909-11.

19. Bürgin-Wolff A, Gaze H, Hadziselimovic F, et al. Antigliadin and antiendomysium antibody determination for coeliac disease. Arch Dis Child 1991;66:941-7.

20. Dieterich W, Laag E, Schöpper $\mathrm{H}$, et al. Autoantibodies to tissue transglutaminase as predictors of celiac disease. Gastroenterology 1998;115: 1317-21.

21. Picarelli A, Triglione $P$, Mariani $P$, et al. Use of a threshold serum level of anti-gliadin antibodies improves diagnostic efficiency of the test in adult coeliac disease but is unreliable as a screening test. Ital J Gastroenterol 1996;28:70-5.

22. Dieterich W, Ehnis $\mathrm{T}$, Bauer $\mathrm{M}$, et al. Identification of tissue transglutaminase as the autoantigen of celiac disease. Nat Med 1997;3: 797-801.

23. Molberg $\varnothing$, McAdam SN, Körner R, et al. Tissue transglutaminase selectively modifies gliadin peptides that are recognized by gut-derived $\mathrm{T}$ cells. Nat Med 1998;4:713-7.

24. Mearin ML, Koning F. Tissue transglutaminase: master regulator of coeliac disease? J Pediatr Gastroenterol Nutr 2003;36:9-11.

25. Troncone R, Maurano F, Rossi M, et al. IgA antibodies to tissue transglutaminase: an effective diagnostic test for coeliac disease. J Pediatr 1999;134:166-71.

26. Hoffenberg EJ, Bao F, Eisenbarth GS, et al. Transglutaminase antibodies in children with a genetic risk for coeliac disease. J Pediatr 2000; 137:356-60.

27. Bonamico M, Tiberti C, Picarelli A, et al. Radioimmunoassay to detect antitransglutaminase autoantibodies is the most sensitive and specific screening method for celiac disease. Am J Gastroenterol 2001;96: 1536-40.

28. al-Bayaty HF, Aldred MJ, Walker DM, et al. Salivary and serum antibodies to gliadin in the diagnosis of celiac disease. J Oral Pathol Med 1989;18:578-81. 
29. O’ Mahony S, Arranz E, Barton JR, Ferguson A. Dissociation between systemic and mucosal humoral immune responses in coeliac disease. Gut 1991;32:29-35.

30. Kelly CP, Fleighery CF, Gallagher RB, Gibney MJ, Weir DG. Mucosal and systemic IgA anti-gliadin antibody in celiac disease. Contrasting patterns of response in serum, saliva, and intestinal secretions. Dig Dis Sci 1991; 36:743-51.

31. Hakeem V, Fifield R, al-Bayaty HF, et al. Salivary IgA antigliadin antibody as a marker for coeliac disease. Arch Dis Child 1992;67:724-7.

32. Rujner J, Socha J, Barra E, et al. Serum and salivary antigliadin antibodies and serum IgA anti-endomysium antibodies as a screening test for coeliac disease. Acta Paediatr 1996;85:814-7.

33. Lähteenoja H, Toivanen A, Raiha I, Syrjanen S, Viander M. Salivary antigliadin and antiendomysium antibodies in coeliac disease. Scand J Immunol 1999;50:528-35.
34. Di Leo M, Weisz G, Ansaldi Balocco N. Serum and salivary antiendomysium antibodies in the screening of coeliac disease. Panminerva Med 1999;41:68-71.

35. Marinello D, Rapa A, Osello R, et al. Celiac disease screening: exploring the iceberg with salivary antigliadin antibodies. J Pediatr Gastroenterol Nutr 2001;32:227-8

36. Nourusis MJ. SPSS PC Advanced Statistics. 1st ed. Chicago: SPSS Inc.; 1986.

37. Seissler J, Boms S, Wohlrab U, et al. Antibodies to human recombinant tissue transglutaminase measured by radioligand assay: evidence for high diagnostic sensitivity for celiac disease. Horm Metab Res 1999;31:375-9.

38. Sblattero D, Florian F, Azzoni E, et al. The analysis of the fine specificity of coeliac disease antibodies using tissue transglutaminase fragments. Eur J Biochem 2002;269:5175-81.

39. Lenander-Lumikari M, Ihalin R, Lähteenoja $H$. Changes in whole saliva in patients with coeliac disease. Arch Oral Biol 2000;45:347-54.

\title{
50 Years Ago in The Journal of Pediatrics
}

\section{CARDIO-ESOPHAGEAL RELAXATION. TREATMENT WITH AN INEXPENSIVE CHAIR}

\author{
Rosenzweig JL. J Pediatr 1954;44:574-7
}

Concepts regarding the recognition and treatment of infantile gastroesophageal reflux have evolved some since Dr Rosenzweig reported the successful management of a young infant with regurgitation by means of a simple chair that permitted the infant to remain in a semirecumbent position at all times. The child was hospitalized and underwent a rather remarkable investigation by current standards before treatment-plain abdominal radiographs, barium enema, two upper gastrointestinal series, and bilateral subdural taps.

Padded with only a cloth diaper, the simple plywood chair with molded Plexiglas back gives more the impression of an instrument to facilitate the interrogation of a felon than therapy for vomiting. A measured drawing for the chair is provided in the article, and I am convinced that it has been used since then by every airline to design coach seats.

Positioning infants with reflux remains problematic. Although the use of infant seats became popular, Orenstein et al elegantly demonstrated that the gastroesophageal junction of the full stomach was submerged when infants were in the semirecumbent position. ${ }^{1}$ Acid reflux, measured by $\mathrm{pH}$ probe test sequentially in the horizontal prone and semirecumbent positions, was increased when the infants were placed in the infant seat reclined to 60 degrees. However, prone positioning, which is more likely to place the gastroesophageal junction above the air-water interface, has been relegated to the back seat due to the risk of sudden infant death syndrome. ${ }^{2}$ As such, gravity has not proved to be the simple solution to infant reflux that Dr Rosenzweig and countless parents and pediatric gastroenterologists have longed for.

Philip E. Putnam, MD, FAAP Division of Pediatric Gastroenterology, Hepatology, and Nutrition Cincinnati Children's Hospital Medical Center

Cincinnati, $\mathrm{OH} 45229$ YMPD778

10.1016/j.jpeds.2004.02.007

\section{REFERENCES}

1. Orenstein SR, Whitington PF, Orenstein DM. The infant seat as treatment for gastroesophageal reflux. N Engl J Med 1983;309:760-3.

2. Kattwinkel J, Brooks J, Myerberg D. Positioning and SIDS. AAP Task Force on Infant Positioning and SIDS. Pediatrics 1992;89:1120-6. 